\title{
The Impact Of Public Funding On Cultural Urban Revitalization
}

\author{
Carl M. Colonna, (ccolonna@cnu.edu), Christopher Newport University
}

\begin{abstract}
The intent of this study is not to defend a preconceived notion that either the market or the public sector is more defensible, but to inform the reader of the public support of the arts. The issue at hand, is whether or not public support of art activities can generate economic development and revenue in an urban regional economy. The scope of this paper will concentrate on the performing and visual artists.

Before proceeding into the investigative background, it is important to establish a protocol statement as to "What Art Is." In western societies, it has been argued that the core of art includes literature, the media, performing and visual art. The fundamental difference in the performing artist and the visual artist is that the former is rewarded with abundance, where the latter by scarcity. There are several reasons why art would be supported. They are as follows: First, art is not necessarily a daily part of our conscious lives. However, large amounts of primary satisfaction received from art can lead to abstractions and ideas that are distributed and used in all parts of the economy. For example, the influence color tones may have on a particular advertising campaign of a particular product line. Second, art is basic to all human endeavors, collectively and individually. It is a link with the past, present and future. Art thus acts as education does-to influence, move, stimulate, and sustain us. Third, if in fact art plays such an important part of our cultural heritage, we do not want our society to experience a deficit in art supply. Baumol and Bowen, in Performing Arts: The Economics Dilemma, make the argument that the labor intensity of the performing arts and its production cannot maintain the proper tempo with the continuous increase in technology in an industrial economy. Thus the performing arts face the stoic reality that operating costs will continue to be above earned revenue. They maintain that investments in performing arts tend to be labor intensive, therefore having the effect of widening the gap between earned revenue and operating costs.
\end{abstract}

Barton Weisbrod, of the University of Illinois, claims that economics of the arts yield an "option value." He defines "option value" as the value assigned to an option to consume, which we may not plan to consume in the near future. This creates a scenario that art works and products would have value to a person who may not personally participate. The myopia nature of the market mechanism may very well fail to allocate and distribute works, which would share these characteristics.

Cultural capital, like real capital, is a stock variable and is subject to depletion. Art is a part of cultural capital, but must be preserved and replenished. Art as cultural capital can and does stimulate cultural tourism. Thus, cultural capital can and should be used as a possible generator of economic activity.

A Heuristic database will be established showing the impact of cultural capital on the growth of art activities, jobs, spending and tourism in urban areas. It is particularly interesting to note that cultural activities may flourish in urban areas while the urban area itself may not flourish economically. 
Demand and supply economies such as those generated by cultural capital can generate economic development through broadening the economic base of an urban area. A recent study showed the impact of forty-five art organizations in Washington, D.C. These organizations accounted for $\$ 619$ million dollars or for every one dollar invested, the art community returned an estimated five dollars and ninety cents into the economy. Thus the art community, and support for it, act as an incubator of broad-based demand and supply economies.

Public support of cultural capital may very well be providing funds for high participation rates in art endeavors, as well as seed monies for low participation rates of art endeavors. The dilemma for the funding of cultural capital in the arts industry is that there has been a significant cut at the federal, state and local levels. This has forced the arts industry to face the need for expanding viewership and private funding. It can be argued that the lure of a clean, productive and community enhancing industry, such as the arts industry, would certainly be aggressively sought by any urban economics development agency.

\section{Introduction}

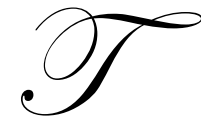

he intent of this study is not to defend a preconceived notion that either the market or the public sector is more defensible, but to inform the reader of the genuine merits and implications of public support of the arts. There is nothing new about public support of the arts in the United States or in other developed economies and societies. The issue at hand, is whether or not public support of art activities can generate economic development and revenue in an urban-regional economy. This paper will attempt to shed some light on the role that art and the public support of art may play in those economies and their infrastructure.

Before proceeding into the investigative research, it is important to recognize that a protocol statement relative to "What Art Is" may be germane since art means many things to many people. In western societies, it has been argued that the core of art includes literature, the media, performing art, and visual art. Viewing art in a broader context could easily include architecture, fashion, handicrafts, preservation, as well as languages. These parameters of art are pervasive in our market places, our leisure, our work, and in our social lives.

The scope of this paper will concentrate on the performing and visual artists. It is important to recognize the fundamental difference between performing and visual artists. In the case of the novelist who is a performing artist, income is a function of primarily two variables. One, the demand of his or her previous works (which establishes his or her preeminence) and two, the quantity of reproductions of his or her work. To illustrate further, the demand for Truman Capote's previously published work is high, therefore establishing his preeminence. Consequently, as additional copies of his book are printed and sold, his rewards increase as he receives royalties from each book purchased. On the other hand, Andrew Wyeth, a painter and therefore a visual artist, has also established his preeminence, but should he choose to reproduce extensively any of his existing works of art, the income generated from that work of art would likely decline. Therefore, it can be observed that the income of the novelist is directly related to the quantity of novels sold, whereas the income of the visual artist is inversely related to the number of the reproductions of his paintings. Thus, the novelist's income is enhanced by the abundance of his or her reproduced novel while the visual artist's income is penalized by such abundance and instead relies upon scarcity for its enhancement.

There are several reasons why art should be supported with public funds. First, art is not necessarily a daily part of our conscious lives. In fact, art is sometimes difficult to define in the lives of most members of society. However, a large amount of primary satisfaction received from art can lead to abstractions and ideas that are dispersed or distributed and used in all parts of the economy. An example of this is the influence color tones in art museums may have on interior decorating design. Second, art is basic to all human endeavors, collectively and indi

Readers with comments or questions are encouraged to contact the authors via email. 
vidually. It is a link with the past, present and future. In this role, art acts as education does- to move us, influence us, sustain us, and stimulate us. Third, if in fact art plays such an important part of our cultural heritage, we do not want our society to experience a deficit in art supply.

A review of basic public finance would clearly categorize art as a quasi-collective good or merit good, which has the characteristic of being mainly private in character, but allocated under major government influence. While merit goods are not equally consumed, they are, however, jointly consumed. In addition, their benefits are subject to the price mechanism. It is likely that a merit good (art) will either be under-produced or not provided at all under the private market mechanism. Public sector decisions regarding the production and distribution of merit goods are often founded on the non-economic forces of the political process. A case then, can be made for the social desirability of government/public support if society has clearly determined that art has a collective value for society. Furthermore, reliance on the private market mechanism could, in essence, skew the emphasis in the art world to commercial art because it is profitable. This would have the impact of stereotyping the cultural role of art to a mercantile emphasis. As a result, this could create an imperfectly competitive art world, which would restrict supply in order to generate greater profitability. In large part such action would not only restrict supply, but stifle creativity and the freedom of choice of artist's in their art endeavors.

Further arguments can be made for public support of performing art based on the so-called cost revenue gaps. These arguments were first developed by William J. Baumol and William G. Bowen in their comprehensive work entitled Performing Arts: The Economic Dilemma. In this work, Professors Baumol and Bowen maintain that the labor intensity of the performing arts and its production cannot maintain the proper tempo with the continuous increases in technology in an industrial economy. Therefore, it's believed that the performing arts are faced with the stoic reality that operating costs will continue to be above earned revenues. It is further argued that while the costs are determined by the economy, the earned revenues are determined by the number of performances and the capacity utilization on the stock of seats at each performance. It is believed that such earnings gaps play a major role on retarding investments in the arts. This dilemma is further intensified by the fact that investments in performing arts tend to be labor intensive, therefore, having the effect of widening the gap between earned revenues and operating costs. This further acts over time to retard particular types of investment, which has the net effect of creating an expansion in the amount by which costs exceed earned revenues.

Burton Weisbrod, of the University of Illinois, claims that economics of the arts yield an "option value." He defines "option value" as the value we assign to an option to consume or to have available a product, which we may not plan to consume in the near future. This creates a scenario that art works and products would have value to a person who may not actually personally participate. It is apparent that the myopic view of the market mechanism based on its right of consumer sovereignty may very well fail to allocate and distribute works, which would share these characteristics. For example, the stock of hospital beds has an option demand characteristic in the sense that we may not want one now or want to have one, yet we certainly want them to be available.

Cultural capital and real capital share many characteristics, one of which is that they are both stocks and are subject to depletion. It becomes particularly important for many reasons. Art is a part of cultural capital but must be preserved and replenished. It also becomes important to recognize that art as cultural capital can and does stimulate cultural tourism. This can be verified, in part, in Southeastern Virginia by the enormous capabilities of the Walter Chrysler Museum's effort to attract tourists on their trek to understanding our culture and past. In addition, the efforts by Ken Burns and his Civil War series, regardless of one's interpretation of its historical accuracy, generated increased viewership for public television over that of the networks. It also acted as a catalyst in a renewed interest in the preservation of historical Civil War events.

Thus, it becomes clear that a society must not only use its cultural capital, but also continue to replenish and restore its stock. The stock variable is not only important from a cultural aspect, but has the possibility of generating economic activity. 
In the absence of public policy in the arts, a fragmentation of art interest may occur, thus causing a breakdown in the production and distribution of art as well as its preservation. Furthermore, an active role played by the national government on art policy clearly establishes a mandate for regional, state and local authorities in which private interest groups may operate.

Art, like education, is predicted on the premise that the consumer is informed and has some appreciation for "the product." Art education, and the understanding of it, is an ongoing process which requires a certain amount of interdependency among each level of consumption in art markets. This differs from the consumption of goods such as a cold glass of milk, in which one looks at the immediate gratification and is either aware or not aware of the low level of knowledge needed for the appreciation and consumption of that good. However, the consumption of a painting like Rauschenberg's "Thaw," is predicted on a full appreciation of Rauschenberg's work. That is to say, consumption is clearly dependent on the historical perceptions of style and form of previous art movements.

Accordingly, if art consumption at each level is enhanced by the earlier understandings of various art movements over time, the initial consumption of art may very well cause the total utility derived from that artwork to increase. This could make the marginal utility of each additional work of art consumed to be greater. First of all, this would enhance the utility of the so called elite, who may be the consumers of art and lead to a phenomenon, which may be further complicated by the fact that, as the consumption of art successfully broadens in a society the prosperous elite appear to narrow their support of the arts. In large part, this is due to the prosperous elite wanting to buy exclusivity. Therefore, as art continues to broaden its appeal, public sector policy must continue to offer incentives, i.e., tax incentives that broaden the patron effect on the arts. A failure to do so may require public policy to take the direction of supporting the arts through tax revenue expenditures as a means to broaden the financial support and reverse the decline in private sector prosperous elite support.

\section{Art As An Instrument Of Economic Development}

Gary Garofalo outlines how art investment compliments revitalization plans for older cities. For the most part, American cities can be characterized as mature or older cities. Certainly the United States has its share of growing cities, (the sunbelt cities for example), but the vast majority can be categorized as mature. It should be noted that the problems associated with older cities tend to be germane only to them. Any Urban Economics textbook would present the case of growing cities as those whose economies generate expansions in productivity that can be measured by output per worker or real per capita income. On the contrary, however, older cities in their amalgamation process begin to provide an unsatisfactory amenity-disamenity mix. As cities become larger, they become efficient producers of goods and services, but lose their desirability as places to live, i.e., more pollution, congestion, and crime. Over time it is possible that these cities will experience comparative disadvantages through decreased productivity. In addition, further changes in technology, unfavorable changes in consumer taste and preferences and changes in public sector expenditures will complicate this phenomenon. Usually cities can reverse this process through changes in capital investments, but this takes a great deal of time and effort. Over time, family income declines as productivity declines. This sets up a scenario where amenities, which are dependent on gains in productivity, will cease to develop.

Garofalo outlines in his article three types of amenities that are affected by low levels of growth and generate an increase in what he calls disamenities:

1. Site-specific amenities, i.e., climate, nearness to beaches, water ways and mountains

2. Size related amenities, i.e., range of occupational choice, neighborhood choice, and large demand and supply economies

3. Purchase amenities, i.e., responsiveness to changes in urban income either public (attractive parks, quality educational institutions, and high quality art institutions) or private (quality restaurants, shopping and commercial activities) 
A review of the literature shows that declines in productivity will have a significant effect on the amenity structure of a city. One only has to ride through old cities and observe that site specific amenities can easily become destroyed and almost non-retrievable. Cultural activities appear to be both size and purchase related and will contract, while disamenities such as crime, deterioration of the stock of housing, and contraction of public services will perpetuate. As a city sees its economic pie become smaller, young and highly skilled workers will leave the area, further intensifying the city's contracting income. This leaves a city, that still has demands being made on its infrastructure, with a shrinking income base; hence, it becomes incapable of maintaining previous levels of quality. There are two basic ways that a community can turn around this downward spiral. They are as follows:

1. Increased productivity through investment in new technology or an expansion on a regional or national basis for the demand of locally produced goods and services

2. An improvement in the amenity-disamenity mix

While an improvement in the amenity-disamenity mix is important, there is little evidence to show that an improvement in this mix by itself will reverse the downward spiral of a city. It is generally recognized that improving the amenity structure is costly as well as difficult to accomplish particularly in the case of site specific amenities, such as cleaning up the environment. It is also recognized that size related amenities would also be costly and difficult to effectively increase, i.e., neighborhood revitalization. Thus one is left with purchase amenities which can either be in the public or the private sector. Today public sector funds are rather sparse, considering the increase spending now and in the future for defense and security needs at the federal and state levels of government. Nor is there much incentive for private sector intervention through investments when the notion of anticipated profits are absent and declines in real wealth effect are impacting middle and upper income levels.

The problems of older communities seem insurmountable. However, there is evidence to show that art activity can have a positive impact on cities, but less so for those that have experienced blight. Therefore, art and art activity cannot be used as a cure all for older declining cities. However, art and art activity can be used in concert with other policies that stimulate growth for such cities.

\section{Support Evidence Of Arts Impact On Economic Development}

The arts can be characterized as a set of industries. As economic entities, it can be seen that these industries may very well have a significant impact on regional and local economies. For instance, a study done by Wake County, North Carolina, entitled, The Economic Impact of the Arts in Wake County, showed the total direct, indirect and induced economic effect of Wake County's nonprofit cultural industries was approximately $\$ 67$ billion. In the last five years, Wake County and Wake County's nonprofit culture industry spent around \$222 million on new construction and building rejuvenation projects. Wake County's nonprofit cultural industry accounts for approximately .5\% of Wake County's employed workforce. This ranks this industry in the top 20 employers in the county. It is also interesting to note that Wake's cultural industry generated an estimated paid visitation of 583,225 people at Wake County's nonprofit cultural programs last year. Nearly $50 \%$ of those who attended these programs were from outside the county and paid on average $\$ 9.48$ per visitation. This has a multiple effect, which generates significant additional income in a local community. In short, they export the cultural activity by bringing in outside consumers to the community who in turn spend external money.

A broad based study of cultural institutions impact on an urban area was done on New York and New Jersey. This study, entitled, The Arts as an Industry: Their Economic Importance to New York-New Jersey Metropolitan Area, was done in 1982 by the Cultural Assistance Center and the Port Authority of New York and New Jersey. Major findings of the 1982 study are as follows:

1. The arts had a $\$ 5.6$ billion dollar annual impact on the New York-New Jersey metropolitan economy with more than $\$ 2$ billion in personal income and 117,000 jobs generated by the arts in the metropolitan area.

2. The art industry constituted a major export industry. It is estimated that $\$ 1.6$ billion was generated annually through the expenditures of those who come to consume art and cultural activities. 
3. Regional art institutions and their non-residential patrons generated an annual total regional income tax and sales tax of $\$ 150$ million.

4. Industries which benefit from economic impact of the cultural expenditures in New York-New Jersey metropolitan area were as follows: real estate, business and professional services, wholesale and retail trade, eating and drinking establishments and hotels and personal services such as utilities.

In 1992, the Port of New York and New Jersey and the Alliance for the Arts did a 10-year update of the 1982 "The Arts As An Industry report. The findings are as follows:

1. The arts had a total economic impact of $\$ 9.8$ billion on the New York-New Jersey metropolitan area in 1992. This is in spite of the fact that the region itself has suffered through difficult times.

2. The arts industries grew $14 \%$ between 1982 and 1992. During the same time period, wages, salaries and royalties grew at a $10 \%$ rate, just short of $\$ 3.5$ billion.

3. Nonprofit cultural industries economic impact grew at about a 38\% rate and thus generating $\$ 2.7$ billion economic impact.

4. The biggest segment of the arts industry in the metropolitan area was film and video production, which created $\$ 3$ billion in income.

5. The 1992-update report revealed that more tourists came to the metropolitan areas, stayed a day longer and generated $\$ 2.3$ billion for the metro-economy.

The two New York and New Jersey studies indicate that nonprofit public support for the arts generated tax revenues and enhanced the economic development to a local economy and regional economy. Thus, it can be seen that art has significant economic value and as an economic instrument, when properly applied, may generate significant economic benefits to an area by stimulating investments and growth.

\section{Concluding Comments}

Numerous studies have shown that nonprofit art institutions are a significant industry in this country. They provide many economic enhancements. Some of these amenities are jobs, income, tourist spending in communities, and broadening of local and state tax base. It is also believed that our local museums, theater groups, and art galleries enhance the quality of life. What also has been revealed by the 1994 National Endowment for the Arts study, is that in Washington, D.C., art investment spending generated a significant multiplier. It is estimated that for every $\$ 1$ invested, the arts community yields an estimated \$5.90 into the local economy. The U.S. Department of Labor estimates that the direct impact of art institutions represent 94 percent of the total U.S. work force. This is quite favorable relative to the direct impact building construction jobs at .98 percent of the 1993 national workforce. What is particularly interesting about the positive economic impact of art institutions on local economies, is these institutions have from the mid-1990s continuously faced cuts in appropriations. To quote Howard Shalwitz of the Woolly Mammoth Theater Company:

"The statistics only confirm what the arts community has known for a long time: When people go to the theater they spend money. Basically, government doesn't get the message. It takes a far sighted vision to see the arts will pay off."

The Washington, D.C. Arena Stage Company faced in 1996, an 86\% cut in funding from the District of Columbia Commission on the Arts and Humanities. The Company successfully made up the short fall through an intensified annual benefit, raising nearly a quarter of a million dollars. It is apparent that art institutions in the United States still obtain a major amount of their support through direct purchases of goods by consumers. Therefore, increasingly art institutions will need to foster the use of polycentric urban configurations which generate economies of scale in knowledge based activities. Some such activities would be research, education and creative arts. As William J. Baumol maintained, art institutions tend to be labor intensive such that their products can not maintain tempo with continuous increase in technology. Art institutions therefore, must move themselves toward technological changes which favor new input combinations and thus generate changes in output. Through these means the culture 
industry can expand its growth and diversify its audiences. Through this diversity of audiences, we must emphasize the value of art education and cultural programs for the younger generations. Through art and art by-products, society provides them with their link from present to the past and the future.

The author would like to express his appreciation to Dr. John E. Anderson, Distinguished Professor of Psychology, Christopher Newport University, for his continuous support of my professional career. To Jamie L. Colonna, my wife, and Kathy Ayers Stovall, my secretary, for their support that made this research possible.

\section{References}

1. Richard A. Musgrove (1959). The Theory of Public Finance.

2. James M. Buchanan and Marilyn R. Flowers (1980). The Public Finances, 33-35.

3. David Cwi (Summer 1979). "Public Support For the Arts: Three Arguments Revisited" The Journal of Behavioral Economics, VIII, 1, 39-68.

4. William S. Hendon (1985). "Arts and Economic Life of the City" Poetics, 14, 125-155.

5. William J. Baumol and William G. Bowen (1966). Performing Arts: The Economic Dilemma, Cambridge and New York: M.I.T. Press and the Twentieth Century Fund.

6. Burton Weisbrod, Secondary Benefits of Education (out of print, but may be found in university libraries).

7. Michael Hutter (1989). "The Arts as Exhaustible Resources: A Theory and its Implications" Cultural Economics 88: A European Perspective, Association for Cultural Economics, Akron OH, 73-80.

8. Bruce Seaman (Summer 1979). "Local Subsidization of Culture! A Public Choice Model Based on Household Utility Maximization" Journal of Behavioral Economics VIII, 1, 93-132. (A special issue of the JBE edited by William S. Hendon and James L. Shanahan.)

9. Gary Garofalo (1979). "Amenity-Disamenity Mix and The Older City," William S. Hendon (ed.), Arts and Urban Development Commentary, Akron: Center for Urban Studies, 30-31.

10. Volker Kirchberg (1995). "Arts Sponsorship and the State of The City: The Impact of Local Socioeconomic Conditions on Corporate Arts Support" Journal of Cultural Economics, V19, N4.

11. "The Economic Impact of the Arts in Wake County," Triangle Business Journal, Raleigh, NC, V16, 16, October 2000.

12. Carl M. Colonna (1992). "Does Art Have Significant Economic Value in Urban Development? A Case for Public Support of Arts” Atlantic Economics Journal, V28, N2.

13. Amy Hersh (October 1993). “Arts Impact is $\$ 9.8$ Billion For New York-New Jersey Economy” Back Stage, V34, N41.

14. Mark Blaug (April 2000). "Where Are We Now on Cultural Economics?” Journal of Economic Surveys, V15, N2.

15. Robert Simonson (March 1996). "Report Trumpets Economic Impact of DC Arts” Back Stage, V37, N10.

16. Barbara Koostra and Patricia Abdou-Diefenderfer (1994). "Artful Business: Economic Impact of Local Nonprofits" Montana Business Quarterly, V32, N2.

17. William S. Hendon (1989). "Supporting the Arts by Public Means" (A paper presented to the Japanese Ministry of Cultural Affairs, Tokyo). 
Notes 